\title{
Positive deviance as a strategy to prevent and control bloodstream infections in intensive care*
}

\author{
Positive Deviance como estratégia na prevenção e controle das \\ infecções de corrente sanguínea na terapia intensiva \\ Positive Deviance como estrategia en la prevención y control de \\ las infecciones de corriente sanguínea en los cuidados intensivos
}

Francimar Tinoco de Oliveira ${ }^{1}$, Maria Manuela Frederico Ferreira ${ }^{2}$, Silvia Teresa Carvalho de Araújo ${ }^{1}$, Amanda Trindade Teixeira de Bessa ${ }^{3}$, Advi Catarina Barbachan Moraes ${ }^{1}$, Marluci Andrade Conceição Stipp ${ }^{4}$

How to cite this article:

Oliveira FT, Ferreira MMF, Araújo STC, Bessa ATT, Moraes ACB, Stipp MAC. Positive deviance as a strategy to prevent and control bloodstream infections in intensive care. Rev Esc Enferm USP. 2017;51:e03212. DOI: http://dx.doi.org/10.1590/S1980-220X2016027403212

* Extracted from the thesis "Intervenções Positive Deviance na terapia intensiva: novas estratégias na gerência do cuidado", Escola de Enfermagem Anna Nery, Universidade Federal do Rio de Janeiro, 2015.

${ }^{1}$ Universidade Federal do Rio de Janeiro, Escola de Enfermagem Anna Nery, Departamento de Enfermagem MédicoCirúrgica, Rio de Janeiro, RJ, Brazil.

${ }^{2}$ Escola Superior de Enfermagem de Coimbra, Conselho para a Qualidade e Avaliação da Unidade Científico Pedagógica de Enfermagem Fundamental, Coimbra, Portugal.

${ }^{3}$ Universidade Federal do Rio de Janeiro, Escola de Enfermagem Anna Nery, Programa de Pós-Graduação, Rio de Janeiro, RJ, Brazil.

${ }^{4}$ Universidade Federal do Rio de Janeiro,

Escola de Enfermagem Anna Nery,

Departamento de Metodologia da

Enfermagem, Rio de Janeiro, RJ, Brazil.

\begin{abstract}
Objective: To describe the application of positive deviance as a strategy to prevent and control bloodstream infections. Method: An intervention study with nursing and medical team members working in an intensive care unit in a university hospital, between June and December 2014. The four steps of the positive defiance methodology were applied: to define, to determine, to discover and to design. Results: In 90 days, 188 actions were observed, of these, $36.70 \%(n=69)$ were related to catheter dressing. In $81.15 \%(n=56)$ of these dressings, the professionals most adhered to the use of flexible sterile cotton-tipped swabs to perform antisepsis at catheter entry sites and fixation dressing. Conclusion: Positive deviance contributed to the implementation of proposals to improve work processes and team development related to problems identified in central venous catheter care.
\end{abstract}

\section{DESCRIPTORS}

Central Venous, Catheters; Infection; Blood Circulation; Nursing Care; Intensive Care Units. 


\section{INTRODUCTION}

Short-term Central Venous catheters (CVCs) are devices inserted via venipuncture into central circulation, i.e., in the lower third of the superior vena cava/right atrium junction ${ }^{(1)}$. They also include devices inserted into large vessels such as the aorta and pulmonary arteries, the superior and inferior vena cava, and the brachiocephalic, internal jugular, subclavian, external iliac, and common femoral arteries ${ }^{(2)}$.

These devices are referred to as "short term" for they lack mechanisms to prevent extraluminal colonization and thus tend to be used for short periods, between 10 and 14 days. It is the most common type of catheter used in intensive care units (ICUs), accounting for approximately $90.0 \%$ of catheter-associated bloodstream infections ${ }^{(1,3)}$.

In these units, infection rates range between $18 \%$ and $54 \%$, rates five to ten times greater than other hospital inpatient units, and their mortality rates vary between $9 \%$ and $38 \%$ due to infections, reaching figures as high as $60 \%{ }^{(4)}$. Thus, educational programs are needed to encourage the participation of multidisciplinary teams in these units to increase adherence to control measures and guide activities that improve inadequate practices, representing an impact strategy to reduce Healthcare-Associated Infections (HAIs) ${ }^{(4)}$.

In this direction, one promising alternative for infection control is the application of the positive deviance (PD) strategy. This concept is grounded in the fact that in any group there are people, referred to as positive deviants, who display unusual yet successful behaviors that enable them to find better solutions to problems shared by the people in the community, who have the same culture, opportunities, difficulties, or challenges ${ }^{(5-6)}$. Their presence allows their community to adopt such innovative behavior, allowing for the measurement of results ${ }^{(5-6)}$.

A basic PD guide orients facilitators on the necessary inquiries, describing the four D's (define, determine, discover, and design) and application tools ${ }^{(6)}$. In this strategy, community members are the experts and all forms of knowledge must be respected and harnessed ${ }^{(6)}$.

Positive deviance should be considered a problem-solving intervention when: the problem is not exclusively technical, but is also relational and requires behavioral and/or social change; the problem is complex and hard to solve, other solutions have not been successful; PD individuals or groups exist; and there is encouragement, sponsorship and commitment of local leadership to solve the question at hand ${ }^{(6-7)}$.

In the health area, the use of PD has shown good results in studies addressing the most diverse themes, such as patient safety ${ }^{(8)}$ and malaria $\operatorname{control}^{(9)}$. Brazilian researchers have reached successful outcomes by using this strategy in increasing adherence to Hand Hygiene $(\mathrm{HH})$ practices in studies that used new technologies to monitor conformity ${ }^{(10-11)}$ and also in preventing drug administration errors ${ }^{(12)}$.

In light of the above, the research question was: When used as a proposal for improving work processes related to CVC insertion and management, is positive deviance an effective strategy to prevent and control bloodstream infections? The following problem was identified and submitted to the PD strategy: high rates of Primary Bloodstream Infection (PBSI) and difficulties presented by the teams in preventing and controlling it.
Therefore, the objective of this study was to describe the application of positive deviance as a strategy to prevent and control bloodstream infections.

\section{METHOD}

This was a longitudinal, prospective study, whose intervention consisted of applying the PD methodology. It was conducted in a university hospital intensive care unit (ICU) located in the North Zone of the municipality of Rio de Janeiro.

The target population consisted of 19 nurses, 51 nursing technicians, and 29 physicians. The following were excluded: professionals on leaves or on vacation; resident health team members; procedures conducted during clinical emergencies and related to peripheral venous access.

Data were gathered between June and December 2014, in three phases. In phase 1 , self-explanatory questionnaires were sent to the professionals via the Internet with questions about their professional characteristics and how they kept up-to-date with scientific developments concerning PBSI prevention. Of the 99 professionals, 77 responded to the questionnaires, and of these, one was discarded for being incomplete. Thus, 76 questionnaires were analyzed, corresponding to a $76.76 \%$ response rate.

In phase 2 , the PD methodology was applied to CVCrelated care practices. The methodology consists of four basic steps, referred to as the four D's. These steps are understood as an itinerate road map(6-7) and are presented schematically in figure 1.

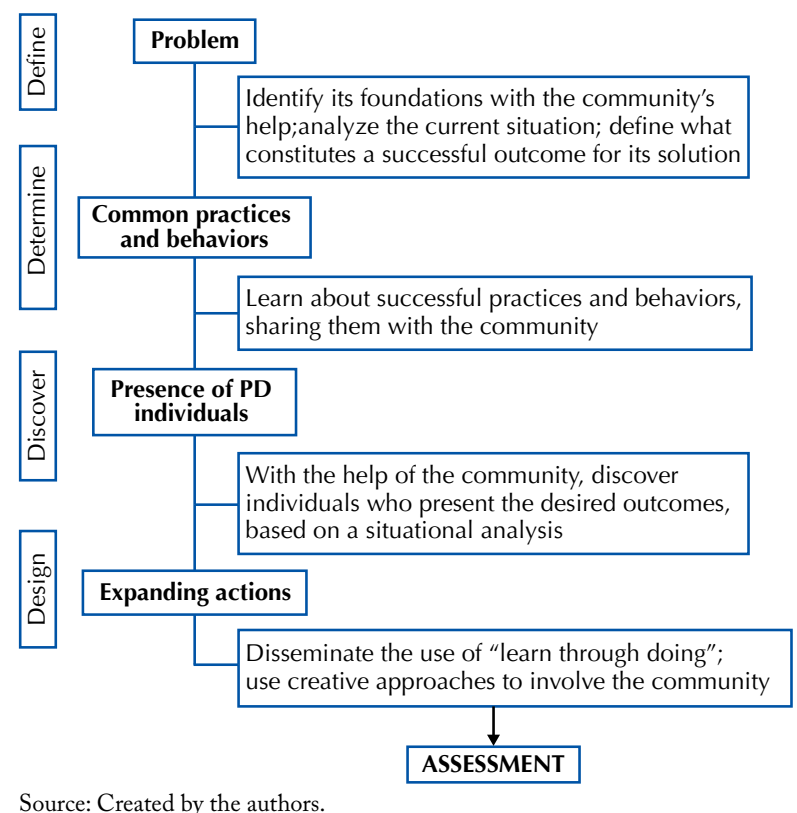

Figure 1 - Guiding model for applying the 4 D's of Positive Deviance - Rio de Janeiro, 2015.

This phase of the study took place in June and August 2014, as explained below:

The first D (Define), defining the fundamentals of the problem, was based on the data from phase 1 . The researchers conducted direct observation of the professionals in their work setting throughout June 2014 to verify the practices employed when inserting and managing CVCs, and to 
identify successful outcomes, difficulties related to CVC care, and possible solutions as identified by the team.

To define the problem and identify PD professionals, the researchers employed a checklist (Chart 1), adapted from the material proposed by Walker, Sterling, Hoke, and Dearden $^{(13)}$, and based on the instructions of the Basic Field Guide $^{(6)}$. Thus, this phase consisted of steps A and B.

Chart 1 - Checklist to assess the problem and identify positive deviants - Rio de Janeiro, 2015.

Step A. Determine whether positive deviance fits the situation (check all that fit)

$\square$ A specific group or population of interest

with a problem has been defined

$\square$ Existing data are available on the group of interest

$\square$ The existing data include information on the problem of interest

$\square$ The data include individuals' behaviors and

perceptions relevant to the problem of interest

$\square$ The intended intervention is focused on individual-level change

$\square$ The problem presented is not exclusively technical, but also

relational, and requires behavioral and/or social change

$\square$ The problem is complex and hard to solve and other solutions have not been successful

$\square$ There is encouragement, sponsorship and commitment from local leadership to solving the problem at hand

Step B. Assess the problem, situation, and risk in the group/setting of interest

1. Assess the problem in the group/setting of interest

a. Analyze the distribution of values (rates, indicators, etc.) for the problem of interest

b. Compare the findings with the data available from other sources (guidelines, manuals, etc.)

2. Carry out a situational analysis

a. Identify situational factors that are potentially relevant to the problem

b. Analyze the normative pattern (established patterns) for these

situational factors

3. Define the key risk factor associated with the problem

a. Select the risk factor

b. Examine the distribution of the risk factor in the group

4. Identify PD professionals

a. Verify the presence of PD individuals or groups in the group/setting of interest, based on the risk and problem classification (professionals who face similar or more difficult challenges in the same care practice routine than the rest of the team, but who find unusual and successful alternatives)

Step C. Identify positive deviants' characteristics and interpret findings

1. Propose possible determinants based on the situational analysis

2. Have members of the group of interest to help interpret the findings and plan the intervention

Adapted from: Walker LO, Sterling BS, Hoke MM, Dearden KA. Applying the concept of positive deviance to public health data: a tool for reducing health disparities. Public Health Nurs. 2007;24:6571-6.

The second $\mathrm{D}$ (determine) consisted of specifying routine team practices and behaviors related to CVC care. Thus, in July 2014, regular visits were conducted to the studied setting, in which the researchers talked with nursing and medical team professionals, including coordinators and leaders. These talks took place during work hours, in both day and night shifts.

The visits were initially conducted over ten consecutive days and then four to five times a week. The researchers respected the work demand during the visit while also approaching as many professionals as possible. The observations yielded one care action related to $\mathrm{CVC}$ dressing and two suggestions of actions to be implemented, one relative to $\mathrm{CVC}$ dressings and the other to the preparation of intravenous (IV) medication.

The third D (discover) took place between July and August 2014, and consisted of identifying the existence of professionals with positive deviant characteristics (Chart 1 , Step B, item 4). The researchers conducted inquiries, directly observed practices, and took notes in field diaries, which resulted in the identification of five positive deviants.

The fourth D (design) was conducted in August and September 2014, in partnership with the hospital's infection control committee, continuing education committee, and sector heads to expand the identified PD actions. The teams used the following tools to share these actions: staff training about $\mathrm{PD}$ actions and good practices in $\mathrm{CVC}$ insertion and management; using didactic resources such as folders and banners; and holding informal meetings with teams to share $\mathrm{PD}$ actions.

The PD individuals helped disseminate the PD actions in the ICU care routine, using the "learning through doing" method. In other words, the actions were conducted in real time during actual care provision in a safe and monitored setting. Initially, the nurses were assisted and guided by the researcher.

Following the implementation of the four D's, PD professionals were contacted on a weekly basis to evaluate the feasibility, adherence and dissemination of the interventions.

In phase 3, following the implementation of $\mathrm{PD}$, professionals were observed once again for 90 days, between September 29,2014 and December 31,2014, during day and night shifts, four times a week, to measure the frequency of the actions. These observations were recorded on specially made forms, applied by the researcher and trained monitors. To ensure the confidentiality of the intervention results, the following procedures were adopted: 1) standardizing the measurement method; 2) training observers; and 3) optimizing the data collection instrument. The data were inserted into Excel $2007^{\circledR}$ spreadsheets and reviewed for possible typing mistakes. The data relative to PD actions (phase 3) were expressed in percentages.

This study was approved by the research ethics committee of the institution of origin (Resolution on. 665.905 of May 27, 2014) and the co-participating institution (Resolution no. 702.350 of June 19,2014), according to resolution 466/2012 of the Brazilian National Health Council on research with human subjects.

\section{RESULTS}

In the first $\mathrm{D}$, analysis of the sociodemographic and professional data showed that most of the nursing and medical team professionals were women (61.84\%). However, when isolated by professional category, this predominance was restricted to the nursing team.

The team was composed of adults (age $>40$ years), with over 14 years since degree and over 8 years of experience in the studied setting. Among the nursing and medical teams, more than $75 \%$ had some type of graduate-level degree, while $50 \%$ of the nursing technicians had complete undergraduate nursing education. 
Regarding knowledge about PBSI, the nurses and doctors kept up to date through articles and conferences, and nursing technicians through the institution's continuing education program, articles, and books, and $9.21 \%$ of this multiprofessional team did not seek any form of update.

In the observations and inquiries carried out, the teams identified low adherence to recommended PBSI prevention practices as a problem situation. These include: intravenous administration without previous disinfection of infusion systems; preparing intravenous medication without previously disinfecting counter tops, trays, and ampoules; bathing patients without protecting the CVC dressings; inserting central venous access with the incorrect use of maximal sterile barrier technique; flawed CVC dressing techniques; lack of supervision for nurses conducting central venous punctures; inadequate hand hygiene; and inappropriate conducts wearing gowns with patients on contact or isolation precautions.

The team described difficulties in preventing and controlling PBSI such as low quality adhesive plasters, which hinder the adhesion of dressings, lack of human and material resources, lack of team training for night shift nurses during their work shift and lack of an institutional safety climate that favors dialogue among professional categories and classes. The team reported that successful outcomes in $\mathrm{CVC}$ care are directly related to solving the existing structural difficulties and improving interaction between health professionals and those responsible for educational processes.

In the second $\mathrm{D}$, a secondary dressing in femoral and jugular accesses with high risk of exposing body fluids was identified as practice with good results. The team also suggested the use of flexible sterile cotton-tipped swabs $\left(\right.$ cotonete $\left.^{\circledR}\right)$ to perform antisepsis of CVCs.
In the third D, five PD professionals were identified: three nurses, one nursing technician and one physician. However, only the nursing professionals proposed actions to be implemented. These were: 1 ) using a flexible sterile cotton-tipped swab (cotonete ${ }^{\circledR}$ ) to perform antisepsis at the CVC insertion site and its fixation when changing dressings; 2) Placing a secondary dressing on jugular and femoral dressings when they present contamination risks (hypersalivation, tracheal secretion, surgical wound secretions or drainage, diuresis in diapers or evacuation/diarrhea; and 3) supplying gauze in separate containers to disinfect counter tops when preparing intravenous medications.

In the fourth $\mathrm{D}$, the continuing education committee publicized a meeting to share the PD actions by e-mail and posters placed throughout the ICU; nonetheless, attendance was low. Therefore, daily visits were made to the setting over 15 days and in both day and night shifts, to approach professionals and disseminate the proposed actions.

The researchers distributed folders with orientations on the sterile cotton swab and secondary dressing technique. Also, a banner was created with CVC insertion and management recommendations as well as $\mathrm{PD}$ actions. It was placed in the sector's internal hallway for 30 days for consultation. After using these resources, adherence to the PD actions increased.

The PD actions observed in phase 3 of the study resulted in 188 procedures. Of these, 148 (78.72\%) were conducted during day shifts and $40(21.28 \%)$ during night shifts; 123 (65.43\%) took place in the surgical ICU and 65 (34.57\%) in the clinical ICU; $42.02 \%(n=79)$ of the procedures were performed by nurses and $57.98 \%(\mathrm{n}=109)$ by nursing technicians, and $119(63.30 \%)$ were relative to the IV drug preparation (Table 1) and 69 (36.70\%) to CVC dressings (Table 2).

Table 1 - Distribution of frequency counter top disinfection by observed procedure and professional category - Rio de Janeiro, Rio de Janeiro, Brazil, 2014.

\begin{tabular}{|c|c|c|c|c|c|c|}
\hline \multirow{3}{*}{ Observed Procedure/Professional } & \multicolumn{6}{|c|}{ Disinfection of Counter Tops $(n=119)$} \\
\hline & \multicolumn{2}{|c|}{ Yes } & \multicolumn{2}{|c|}{ No } & \multicolumn{2}{|c|}{ Total } \\
\hline & $\mathbf{n}$ & $\%$ & $\mathbf{n}$ & $\%$ & $\mathbf{n}$ & $\%$ \\
\hline Drug preparation/Nurse & 05 & 4.20 & 05 & 4.20 & 10 & 8.40 \\
\hline Drug preparation/Nurs. tech.* & 54 & 45.38 & 55 & 46.22 & 109 & 91.60 \\
\hline Total & 59 & 49.58 & 60 & 50.42 & 119 & 100.00 \\
\hline
\end{tabular}

Source: Data from the study.

Legend: *Nursing technician.

Table 2 - Distribution of the use of sterile cotton-tipped swabs and secondary dressings in central venous access - Rio de Janeiro, Rio de Janeiro, Brazil, 2014.

\begin{tabular}{|c|c|c|c|c|c|c|c|c|c|c|c|c|}
\hline \multirow{4}{*}{$\begin{array}{l}\text { Entry } \\
\text { site }\end{array}$} & \multicolumn{12}{|c|}{ Dressings $(n=69)$} \\
\hline & \multicolumn{6}{|c|}{ Sterile Swab** } & \multicolumn{6}{|c|}{ Secondary Dressing } \\
\hline & \multicolumn{2}{|c|}{ Yes } & \multicolumn{2}{|c|}{ No } & \multicolumn{2}{|c|}{ Total } & \multicolumn{2}{|c|}{ Yes } & \multicolumn{2}{|c|}{ No } & \multicolumn{2}{|c|}{ Total } \\
\hline & $\mathbf{n}$ & $\%$ & $\mathbf{n}$ & $\%$ & $\mathbf{n}$ & $\%$ & $\mathbf{n}$ & $\%$ & $\mathbf{n}$ & $\%$ & $\mathbf{n}$ & $\%$ \\
\hline Subclavian & 08 & 11.59 & 02 & 2.90 & 10 & 14.49 & 00 & 00 & 10 & 14.49 & 10 & 14.49 \\
\hline Internal Jugular & 27 & 39.13 & 05 & 7.25 & 32 & 46.38 & 03 & 4.35 & 29 & 42.03 & 32 & 46.38 \\
\hline Femoral & 21 & 30.43 & 06 & 8.70 & 27 & 39.13 & 09 & 13.04 & 18 & 26.09 & 27 & 39.13 \\
\hline Total & 56 & 81.15 & 13 & 18.84 & 69 & 100 & 12 & 17.39 & 57 & 82.61 & 69 & 100 \\
\hline
\end{tabular}

Source: Data from the study.

Legend: ${ }^{*} \mathrm{PD}$ - Positive Deviance;*'Sterile cotton-tipped swab - Cotonete ${ }^{\circledR}$. 
Regarding the distribution of drug preparation, most actions were performed by nursing technicians. However, the isolated assessment of counter top disinfection among professional categories did not present any differences between their proportions.

In terms of dressings, sterile cotton-tipped swabs were used in $81.15 \%(n=56)$ of the dressings observed, especially in catheters inserted in the internal jugular vein (39.13\%), and less used in femoral lines (8.70\%). Among the reasons indicated by the nurses for not using sterile cotton-tipped swabs, in $11.59 \%(n=8)$ of cases this material was not available in the setting. Answers such as "I forgot to use them" and "I prefer not to use them" corresponded to $7.25 \%(n=5)$ of total dressings. The secondary dressing was not used in $82.61 \%(n=57)$ of the times, however $27.13 \%(n=18)$ of these lines did not have the indication for this action.

\section{DISCUSSION}

Considering the first $\mathrm{D}$ in the studied setting, even though prior attempts had been made to reduce CVCassociated infections, low adherence of professionals indicated the need for behavioral change ${ }^{(14)}$.

Educational processes and health team training are important tools, but it is also necessary to assess CVCrelated care competencies and professional adherence to infection prevention practices ${ }^{(15-19)}$. Under these circumstances, the PD approach proved to be fit, given that its interventions focus on individual behavior change ${ }^{(6,11)}$.

Regarding the identification of practices with good outcomes and professionals with PD characteristics (second and third D's), only nursing team professionals proposed PD actions that were implemented and assessed in this study. These actions are intimately related to nursing care and with CVC management. In other words, despite the methodology adopted, no actions were identified or proposed for catheter insertion. This may be due to the fact that it was the team's first contact with PD.

In the health area, PD has been used to research hand hygiene practice in interventions with multidisciplinary teams ${ }^{(9-12)}$, to assess nursing team adherence to this practice $^{(8)}$, to involve nurses in the improvement of clinical and administrative outcomes in health systems, and to reduce the incidence of bloodstream infections ${ }^{(20)}$, among others ${ }^{(5)}$.

All of the steps of this intervention were shared beforehand with local leadership, the hospital infection control committee and the continuing education committee to establish a support network involving both the professionals responsible for providing the necessary resources and conditions and the volunteers who participated in the process.

The head of nursing included flexible cotton-tipped swabs into the weekly quota of ICU materials and made the necessary contacts with the sterile supply center to provide packages with four sterilized swabs. The nursing team began requesting these packages routinely at the beginning of each day or night shift to perform dressings. A greater number of containers with gauze were also made available to disinfect counter tops and trays when preparing IV medication, favoring work logistics.
Using the sterile swab and applying secondary dressings are actions that do not require significant financial investment, as these materials are already available at the institution. However, their implementation using the "learn through doing" technique requires dedicated and continuous monitoring. Thus, the results obtained in this study corroborate the proposal presented in the Basic Field Guide to the Positive Deviance Approach ${ }^{(6)}$.

Considering the procedures submitted to $\mathrm{PD}$ actions, the use of gauze to disinfect counter tops during IV drug preparation was effectively carried out in only half of the observed procedures. During CVC dressing change, the use of flexible sterile cotton-tipped swabs was the most predominant PD action, as secondary dressings are only indicated in specific cases and, therefore, occurred less frequently.

In the studied setting, IV drug administration was conducted predominately by the nursing technicians. The results show that $8.40 \%$ of these actions were conducted by nurses; however, regardless of professional category, the frequency distribution for performing (or not performing) counter top disinfection before drug preparation among nurses and nursing technicians was practically identical ${ }^{(14)}$.

These results corroborate good practices in central venous catheterization. Ensuring aseptic control when preparing parenteral solutions to prevent fluid contamination and bloodstream infections is of extreme importance, thus rendering these practices essential ${ }^{(1-2)}$. The results of this study suggest that a new cycle of the PD approach should be conducted, in which the 4 D's are specifically focused on the team's deficiencies. The addition of these new steps can help professionals improve care processes and advance patient care and safety ${ }^{(11)}$.

The use of sterile cotton-tipped swabs to aid in disinfection entry site and lower region of the CVC fixation dressing was the greatest highlight of this study, both in the frequency of its use and adherence by the nursing team. Its use began to be recommended as part of the prescribed nursing routine with CVC patients and, until the time of study were still in place, having been extended to other inpatient units, which is a significant outcome of this action.

The only study found in the literature on flexible cottontipped swabs, published 16 years ago, addressed its use as a lower-costing alternative to the sterile swab. They determined that the delicate nature of these swabs enabled antisepsis in hard-to-reach places surrounding the catheter that was not possible using the standard technique. In this study, the team began to use the sterile cotton-tipped swab routinely and care provision improved, achieving infection control ${ }^{(21)}$.

In each step of the dressing change, professionals must be meticulous in applying the sterile technique and evaluating the entry site, and verifying the presence of hyperemia and/or secretions, bleeding, leakage, broken sutures, or CVC instability ${ }^{(1-2,4)}$. Secretions, clots, and blood residue on the catheter or under the fixation dressing must be removed, and the flexible swab can reach areas that sterile gauze cannot.

Given the predominance of internal jugular CVCs (46.38\%) in this study, the swab was used most frequently in this form of access; however, even though $39.13 \%$ of the CVCs were inserted in the femoral artery, swabs were used 
less frequently in this form of access. The subclavian vein was the less frequent form of access, despite current recommendations indicating it as the first choice for CVC entry site $^{(2,4)}$. This finding corroborates the results of phase 1 , which indicated that despite knowledge about the recommended use of subclavian vein as the ideal entry site, with the exception of short-term hemodialysis catheters ${ }^{(2,4)}$, only $50 \%$ of the physicians answered that they abided by this recommendation when choosing central venous puncture sites ${ }^{(14)}$.

Risk of complication must be taken into account when choosing CVC puncture sites. Considering that this study was conducted at a university hospital, the femoral vein may have been more commonly used than the subclavian due to the risk of mechanical complications related to anatomical conditions.

In terms of the complications related to CVC insertion site, the literature states that internal jugular, subclavian, and femoral vein catheters are more vulnerable to embolisms and hemorrhage; the jugular and subclavian veins are safer in terms of bacterial contamination, but susceptible to risk of pneumothorax, hemothorax, and air embolisms; and the femoral vein is less recommended due to greater incidence of bacterial infection and thrombosis, in addition to limiting patient movement ${ }^{(22)}$.

Secondary dressings are indicated in specific situations, which can justify the lower overall frequency and greater usage in femoral accesses. The main function of dressings is to keep the catheter insertion site clean and dry, and stabilize it, and its application must be catered to each individual, meeting the characteristics and demands of each patient ${ }^{(1)}$.

The results indicate that the interventions should be assessed over a longer period to obtain frequencies that would enable a statistical analysis of their impact. Nonetheless, a favorable trend was observed towards their adherence in the setting. The studies presented above that adopted PD methodology had longer intervention times than in the present study (8-12), in addition to conducting pre - and post-intervention comparisons. Among these studies, those focused on $\mathrm{HH}$ adherence also conducted an initial approach using the PD strategy and over time, expanded the approach to other settings.
Thus, given the possibility of advancing this investigation in the studied setting, the researchers plan to conduct new verifications for comparative effects with a greater exploration of the feedback loop, which in combination with the ongoing use of $\mathrm{PD}$, can result in higher adherence rates ${ }^{(9-10)}$. Combined strategies aimed at CVC care can increase collaboration among professionals in the ICU, the institution and even other centers ${ }^{(8,20-23)}$.

\section{CONCLUSION}

The implementation of the positive deviance methodology enabled a new approach to CVC care. Important care aspects were identified as opportunities for improvement, suggesting the need for greater investment in the theoreti$\mathrm{cal} /$ practical knowledge of the health team about preventing CVC-associated infections, specifically in terms of information, capacity building and training.

The implementation of PD allowed for the establishment of a support network with the local nursing leadership, who provided the necessary support and removed barriers to the implementation of the proposed actions. This engagement was essential and promoted opportunities for practicing PD actions in a safe and monitored environment.

Up to the date of this article, the implemented actions were still being practice in the ICU and the use of the flexible sterile swab was widely disseminated, including other inpatient units in the same institution. The maintenance of these actions, in addition to the inclusion of new ones, requires ongoing monitoring and assessment, as recommended by the $4 \mathrm{D}$ methodology.

Finally, the PD methodology helped implement proposals to improve work processes and team development relative to the problems identified in $\mathrm{CVC}$ care, generating adherence to better care practices.

Limitation: In August 2014, the hospital received patients colonized with carbapenem-resistant Enterobacteriaceae (CRE), and they were placed in the ICU.Thus, the unit's patient profile changed, resulting in a reduced number of inpatient beds, especially for surgical patients. This fact may have generated fewer opportunities for conducting the proposed actions.

\section{RESUMO}

Objetivo: Descrever a aplicação do Positive Deviance como estratégia na prevenção e no controle da infecção de corrente sanguínea. Método: Estudo de intervenção realizado na Unidade de Terapia Intensiva de um hospital universitário, com os membros das equipes de enfermagem e médica, de junho a dezembro de 2014. Foram aplicados os quatro passos da metodologia Positive Deviance: Definir, Determinar, Descobrir e Desenhar. Resultados: Em 90 dias 188 ações foram observadas, destas, 36,70\% (n=69) estavam relacionadas aos curativos dos cateteres. Em 81,15\% ( $\mathrm{n}=56)$ desses curativos, o uso da haste flexível estéril para realização da antissepsia do local de inserção do cateter e de sua placa de fixação foi a ação de maior adesão. Conclusão: O Positive Deviance auxiliou na implementação de propostas de melhorias de processo de trabalho e no desenvolvimento da equipe para os problemas identificados no cuidado com o cateter venoso central.

\section{DESCRITORES}

Cateteres Venosos Centrais; Infecção; Circulação Sanguínea; Cuidados de Enfermagem; Unidades de Terapia Intensiva.

\section{RESUMEN}

Objetivo: Describir la aplicación del Positive Deviance como estrategia en la prevención y control de la infección de corriente sanguínea. Método: Estudio de intervención realizado en la Unidad de Cuidados Intensivos de un hospital universitario, con los miembros de los equipos de enfermería y médico, de junio a diciembre de 2014. Fueron aplicados los cuatro pasos de la metodología Positive Deviance: Definir, Determinar, Descubrir y Dibujar. Resultados: En 90 días 188 acciones fueron observadas; de estas, 36,70\% (n=69) estaban 
relacionadas con los apósitos de los catéteres. En el 81,15\% (n=56) de esos apósitos, el empleo del bastoncillo estéril para la realización de la antisepsia del sitio de inserción del catéter y de su placa de fijación fue la acción de mayor adhesión. Conclusión: El Positive Deviance ayudó la implantación de propuestas de mejorías de proceso laboral y el desarrollo del equipo para los problemas identificados en el cuidado con el catéter venoso central.

\section{DESCRIPTORES}

Catéteres Venosos Centrales; Infección; Circulación Sanguínea; Atención de Enfermeria; Unidades de Cuidados Intensivos.

\section{REFERENCES}

1. Kusahara DM, Peterlini MAS. Cateteres intravenosos centrais de curta permanência. In: Harada MJCS, Pedreira MLG, editoras. Terapia intravenosa e infusões. São Caetano do Sul: Yendis; 2011. p. 230-50.

2. O'Grady NP, Alexander M, Burns LA, Dellinger EP, Garland J, Heard SO, et al. Guidelines for the Prevention of Intravascular CatheterRelated Infections [Internet]. Atlanta: CDC; 2011 [cited 2015 Nov 16]. Available from: http://www.cdc.gov/hicpac/pdf/guidelines/bsiguidelines-2011.pdf

3. Miralha MAP, Cruz ICF. A segurança do paciente na prevenção de infecção de cateter venoso central: revisão sistematizada da literatura para um protocolo clínico. J Specialized Nurs Care [Internet]. 2016 [citado 2016 jun. 30];8(1):1-10 [citado 2016 jun. 30]. Disponível em: http://www.uff.br/jsncare/index.php/jsncare/article/view/2820/691

4. Centers for Disease Control and Prevention; Central Line Associated Bloodstream Infection. Bloodstream infection event [Internet]. Atlanta: CDC; 2014 [cited 2015 Nov 16]. Available from: http://www.cdc.gov/nhsn/PDFs/pscManual/4PSC_CLABScurrent.pdf

5. Baxter R, Taylor N, Kellar I, Lawton R. What methods are used to apply positive deviance within healthcare organisations? A systematic review. BMJ Qual Saf. 2016;25(3):190-201.

6. Pascale R, Sternin J, Sternin M. The power of positive deviance: how unlikely innovators solve the world`s toughest problems. Boston: Harvard Business Press; 2010.

7. Positive Deviance Initiative. The impact of the Positive Deviance [Internet]. [cited 2016 Apr 27]. Available from: http://www.positivedeviance. org/about_pd/impact.html

8. Lawton R, Taylor N, Clay-Williams R, Braithwaite J. Positive deviance: a different approach to achieving patient safety. BMJ Qual Saf. 2014;23(11):880-3.

9. Shafique M, Edwards HM, De Beyl CZ, Thavrin BK, Min M, Roca-Feltrer A. Positive deviance as a novel tool in malaria control and elimination: methodology, qualitative assessment and future potential. Malar J. 2016;15:91

10. Marra AR, Edmond MB. New technologies to monitor healthcare worker hand hygiene. Clin Microbiol Infect. 2014;20(1):29-33.

11. Marra AR, Camargo TZS, Magnus TP, Blaya RP, Santos GB, Guastelli LR, et al. The use of real-time feedback via wireless technology to improve hand hygiene compliance. Am J Infect Control. 2014;42(6):608-11.

12. Ferracini FT, Marra AR, Schvartsman C, Santos OFP, Victor ES, Negrini NMM, Borges Filho WM, Edmond MB. Using Positive Deviance to reduce medication errors in a tertiary care hospital. BMC Pharmacol Toxicol. 2016;17(1):36.

13. Walker LO, Sterling BS, Hoke MM, Dearden KA. Applying the concept of positive deviance to public health data: a tool for reducing health disparities. Public Health Nurs. 2007;24(6): 571-6.

14. Oliveira FT, Stipp MAC, Silva LD, Frederico M, Duarte SCM. Behavior of the multidisciplinary team about Bundle of Central Venous Catheter in Intensive Care. Esc Anna Nery. 2016;20(1):55-62.

15. Cooper K, Frampton G, Harris P, Jones J, Cooper T, Graves N, et al. Are educational interventions to prevent catheter-related bloodstream infections in intensive care unit cost-effective? J Hosp Infect. 2014;86(1):47-52.

16. Ider BE, Adams J, Morton A, Whitby M, Muugolog T, Lundeg G, et al. Using a checklist to identify barriers to compliance with evidencebased guidelines for central line management: a mixed methods study in Mongolia. Int J Infect Dis. 2012;16(7):e551-7.

17. Moureau N, Lamperti M, Kelly LJ, Dawson R, Elbarbary M, van Boxtel AJH, et al. Evidence-based consensus on the insertion of central venous access devices: definition of minimal requirements for training. Br J Anaesth. 2013;110(3):347-56.

18. Weaver SJ, Weeks K, Pham JC, Pronovost PJ. On the CUSP: Stop BSI: evaluating the relationship between central line associated bloodstream infection rate and patient safety climate profile. Am J Infect Control. 2014;42(10 Suppl):S203-8.

19. Pereira FMV, Malaguti-Toffano SE, Silva AM, Canini SRMS, Gir E. Adherence to standard precautions of nurses working in intensive care at a university hospital. Rev Esc Enferm USP. 2013;47(3):681-7. DOI: http://dx.doi.org/10.1590/S0080-623420130000300023

20. Lindberg C, Downham G, Buscell P, Jones E, Peterson P, Krebs V. Embracing collaboration: a novel strategy for reducing bloodstream infections in outpatient hemodialysis centers. Am J Infect Control. 2013;41(6):513-9.

21. Liedke DCF, Stier CJN. Uso de hastes flexíveis na prevenção de infecção em pacientes com cateter venoso central. Cogitare Enferm. 2000;5(n.esp):41-5. DOI: http://dx.doi.org/10.5380/ce.v5i1.44867

22. Barretta LM, Beccaria LM, Cesarino CB, Pinto MH. Complications of central venous catheter in patients transplanted with hematopoietic stem cells in a specialized service. Rev Lat Am Enfermagem. 2016;24:e2698.

23. Gary JC. The wicked question answered: positive deviance delivers patient-centered care. Dimens Crit Care Nurs. 2014;33(3):142-50. 